\title{
Correspondence
}

\section{Innovative and effective approaches to crisis services}

As a patient, I was recently under the care of a London crisis intervention team. The compassion of the individual staff members was negated by systemic flaws in the way the service was delivered.

The experience was very unsettling. Different staff would arrive twice daily at my home because shift patterns would not allow the same workers to see me regularly. Consequently, a constructive, consistent relationship with members of the crisis team was not possible. A stream of strangers entered my small, cramped flat, and the crisis team actually became part of my mental trauma.

The problem with the crisis team as an institution is that it is about cost-cutting rather than caring. It felt like a mere sticking plaster on a huge mental wound.

While cost-cutting remains the ethos, patients are bound to suffer. The loss of in-patient beds is putting pressure on community services that they cannot sustain. Cost-cutting may masquerade as streamlined efficiency and effectiveness, but it is really a way to hobble and cripple psychiatric provision.

Good treatment cannot be delivered without flexibility and variety, both community-based and hospital-based. The crisis team concept is an ineffective half-way (and half-baked!) house between community and hospital.

\section{Declaration of interest \\ The author is a psychiatric patient.}

The name and address of the London trust and the name and address of the patient have been withheld for confidentiality reasons. To contact the author, please email pb@rcpsych.ac.uk

doi: $10.1192 /$ pb.34.10.452

\section{British television viewers, cover your ears!}

While watching a well-known, popular soap on the BBC recently, I was disgusted to hear one of the characters with recently diagnosed bipolar affective disorder being referred to by another character as a 'mentalist'.

Both entertainment and news media seem to model negative reactions to the mentally ill, including fear, rejection, derision and ridicule. The consequences of negative media images for people who have a mental illness are profound. They impair self-esteem, help-seeking behaviours, medication adherence and overall recovery. The Royal College of Psychiatrists, healthcare professionals working in mental health and mental health charities such as Mind and Rethink work hard to challenge the stigma and negative attitudes towards mental illness. How disappointing therefore that the scriptwriters of this soap, a programme watched by millions of viewers, see fit to contradict these efforts by using such a derogatory term to describe someone with bipolar affective disorder.

Negative media reports have been shown to contribute to negative attitudes towards people with mental illness. ${ }^{2}$ As adults, we have the presence of mind and sound judgement to recognise that the use of the term 'mentalist' is both socially unacceptable and insulting. But the minds of the younger generation are more impressionable. We do not want children thinking it is all right to describe someone with mental illness as 'a mentalist' because they have heard the term used on the television and come to believe it must be acceptable to use in everyday life. The writers of television programmes watched by both young and old alike have an important role to play in 'shaping the minds' of the youngsters of today. They should seek to show mental illness in a positive rather than negative light and thus help to eradicate rather than contribute to its stigmatisation.

1 Stuart H. Media portrayal of mental illness and its treatments: what effect does it have on people with mental illness? CNS Drugs 2006; 20 99-106.

2 Thornton JAA, Wahl OF. Impact of a newspaper article on attitudes towards mental illness. J Community Psychol 2008; 24: 17-25.

Declan L. Hyland, Foundation year 2 doctor, Aintree University Hospitals NHS Foundation Trust, Liverpool, email: declan.hyland@nhs.net

doi: $10.1192 / p b .34 .10 .452 a$

\section{Psychiatry, religion and spirituality: a way forward}

Recent correspondence in The Psychiatrist suggests that there are conflicting, or perhaps polarised, opinions about the role of spirituality and religion in UK psychiatric practice. In their latest contribution to the debate, Cook et al ${ }^{1}$ state that it is important not to rely only on impressions derived from clinical experience but also to refer to evidence-based research and reviews. If we cannot eliminate bias in our interpretation of these findings, we can at least minimise it.' We agree.

However, although rhetoric and the selective interpretation of evidence are an intrinsic part of scientific discourse, spirituality and religion cause particular problems. Most professionals have deep-seated views that are unlikely to be affected by evidence, no matter how compelling. For example, whereas Koenig's review of the literature ${ }^{2}$ suggests 'modest positive effects of religious faith', we prefer Richard Sloan's review ${ }^{3}$ of similar literature, the conclusions of which can be paraphrased thus: efforts to integrate religion into medical practice are based on bad science, bad medicine and bad religion. We find Sloan more convincing than Koenig, but we note that Sloan's conclusions resonate with our pre-existing attitudes and beliefs.

We have previously argued that psychiatry should only attempt to resolve problems that cannot be dealt with effectively by other means. Although mental health professionals have demonstrable skills in the relief of suffering caused by mental disorders, there is no evidence that we have any answers to problems of human happiness. There are other, non-clinical, routes to happiness. Thus, we agree with Sloan et $a l_{,}^{4}$ who have argued that even if the evidence shows that religious faith promotes well-being, it is still inappropriate for clinicians to actively promote religion or to unnecessarily interfere in spiritual matters.

These ideas are more closely related to modern medical values than to science. In any case there is no reliable evidence with regard to the consequences of integrating spirituality/ 